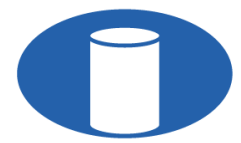

IBRACON Structures and Materials Journal

Revista IBRACON de Estruturas e Materiais

ORIGINAL ARTICLE

\title{
A simplified approach to reliability evaluation of deep rock tunnel deformation using First-Order Reliability Method and Monte Carlo simulations
}

\author{
Uma abordagem simplificada para avaliação de confiabilidade em túneis rochosos \\ profundos utilizando o Método de Confiabilidade de Primeira Ordem e Simulações \\ de Monte Carlo \\ Caio Cesar Cardoso da Silva ${ }^{\mathrm{a}}$ \\ Mauro de Vasconcellos Real ${ }^{\mathrm{b}}$ (D) \\ Samir Maghous ${ }^{\mathrm{c}}$ (D)

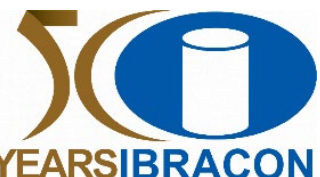

${ }^{a}$ Universidade Federal do Rio Grande do Sul, Programa de Pós-graduação em Engenharia Civil, Porto Alegre, RS, Brasil

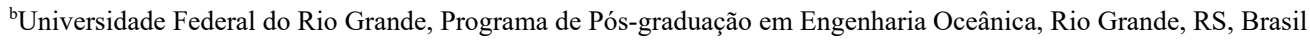

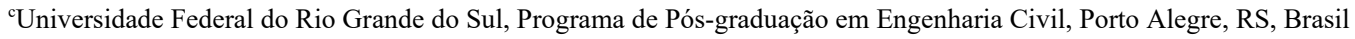

Received 13 March 2021

Accepted 19 April 2021

\begin{abstract}
The Monte Carlo simulation (MCS) and First-Order Reliability Method (FORM) provide a reliability analysis in axisymmetric deep tunnels driven in elastoplastic rocks. The Convergence-Confinement method (CV-CF) and Mohr-Coulomb (M-C) criterion are used to model the mechanical interaction between the shotcrete lining and ground through deterministic parameters and random variables. Numerical models synchronize tunnel analytical models and reliability methods, whereas the limit state functions control the failure probability in both ground plastic zone and shotcrete lining. The results showed that a low dispersion of random variables affects the plastic zone's reliability analysis in unsupported tunnels. Moreover, the support pressure generates a significant reduction in the plastic zone's failure, whereas the increase of shotcrete thickness results in great reduction of the lining collapse probability.
\end{abstract}

Keywords: axisymmetric deep tunnels, shotcrete lining, CV-CF method, MCS, FORM.

\begin{abstract}
Resumo: Este trabalho propõe uma análise de confiabilidade em túneis profundos axissimétricos, escavados em maciços rochosos elasto-plásticos, utilizando o Método de Confiabilidade de Primeira Ordem e simulações de Monte Carlo. O método Convergência-Confinamento (CV-CF) e o critério de Mohr-Coulomb (M-C) são utilizados para modelar analiticamente a interação mecânica entre o revestimento de concreto projetado e o maciço escavado, através de parâmetros determinísticos e variáveis aleatórias. Modelos numéricos são sincronizados com os modelos analíticos de túneis e os métodos de confiabilidade, enquanto as funções estado-limite definem a probabilidade de falha na zona plástica do maciço rochoso e no revestimento de concreto projetado. Os resultados mostram que uma baixa dispersão das variáveis aleatórias afeta a confiabilidade da zona plástica na análise de túneis sem revestimento. Além disso, a pressão de suporte gera uma redução significativa na falha da zona plástica, enquanto o aumento da espessura do concreto projetado resulta em uma grande redução da probabilidade de colapso do revestimento.
\end{abstract}

Palavras-chave: túneis profundos axissimétricos, concreto projetado, método CV-CF, simulações de Monte Carlo, FORM.

How to cite: C. C. C. Silva, M. V. Real, and S. Maghous, “A simplified approach to reliability evaluation of deep rock tunnel deformation using First-Order Reliability Method and Monte Carlo simulations," Rev. IBRACON Estrut. Mater., vol. 15, no. 1, e15104, 2022, https://doi.org/10.1590/S1983-41952022000100004

Corresponding author: Caio Cesar Cardoso da Silva. E-mail: caiocesarcardosodasilva@gmail.com

Financial support: This study was financed in part by the Coordenação de Aperfeiçoamento de Pessoal de Nível Superior - Brazil (CAPES) - Finance Code 001. Conflict of interest: We wish to confirm that there are no known conflicts of interest associated with this publication. 


\section{INTRODUCTION}

Several geotechnical and structural parameters are involved in deep tunnels and underground excavation analysis, which induce high or undefined structural risks. The reliability analysis evaluates structural failure probabilities in tunnels by applying random and deterministic parameters in analytical solutions or numerical methods.

The first serious discussions and analyses of tunnel reliability emerged during the 1990s with [1]-[6]. Low and Tang [5] focused on identifying and evaluating the reliability and risk parameters through numerical procedures, synchronizing reliability codes developed in software like Microsoft Excel, and analytical methods for axisymmetric tunnels. This work used the First Order Reliability Method (FORM) and Monte Carlo Simulation (MCS) in the reliability study. Low and Tang [7], [8] developed and improved the FORM numerical procedures. Li and Low [9] conducted a series of reliability analyses of an axisymmetric tunnel, considering normal and non-normal random variables of the rock mass and the Low and Tang [5] FORM algorithm. The internal pressure produces a reduction of risk; moreover, the authors checked the reliability results using MCS. Lü and Low [10] and Song et al. [11] studied the reliability of axisymmetric tunnels through the FORM and Second-Order Reliability Method (SORM), synchronizing these methods with analytical solutions based on Mohr-Coulomb (M-C) and Hoek Brown criteria.

Bjureland et al. [12] applied the MCS associated with the Convergence-Confinement method (CV-CF method) to analyze the failure probability in a shotcrete lining of a circular tunnel. The $\mathrm{M}-\mathrm{C}$ criterion describes the plasticity behavior for the excavated rock mass, and the Observational method checks the failure results, verifying the necessity of putting into action security measures.

The present paper analyses the reliability methods impact on analytical tunneling methods, examining two different tunnels with statistical and deterministic distinct parameters. This study aims to investigate the reliability results of the plastic zone excavation and the shotcrete lining for both tunnels, establishing interesting comparisons between them. For this, the reliability procedures associate the use of the FORM Low and Tang method, developed in Low and Tang [5], and the MCS. The reliability algorithms, developed in VBA and MATLAB codes, employ two analytical methodologies for axisymmetric tunnels: the M-C plasticity criterion for excavated rock masses and the CV-CF method to analyze the interaction between the shotcrete lining and rock mass.

\section{RELIABILITY CONCEPTS}

\subsection{Reliability Index: The Low and Tang FORM Interpretation}

Hasofer and Lind [13] defined the second-moment reliability index $\beta$ as a better approach in civil engineering design in comparison with usual safety factors [7]. Equation 1, proposed by Low and Tang [7], represents the matrix formulation of the Hasofer-Lind reliability index for correlated normal variables:

$$
\beta=\min _{x \in F} \sqrt{\left[\frac{x_{\mathrm{i}}-\mu_{\mathrm{i}}}{\sigma_{\mathrm{i}}}\right]^{T}[\mathbf{R}]^{-1}\left[\frac{x_{\mathrm{i}}-\mu_{\mathrm{i}}}{\sigma_{\mathrm{i}}}\right]}
$$

where $x_{\mathrm{i}}$ is the set of random variables of the vector $\boldsymbol{x}, \mu_{\mathrm{i}}$ is the set of mean values of the vector $\boldsymbol{\mu}$, and $\sigma_{\mathrm{i}}$ is the set of standard deviations of the vector $\sigma$. The domain $F$ represents the failure regions, whereas $[\mathbf{R}]$ is the correlation matrix, expressed by [14]:

$[\mathbf{R}]=\left[\begin{array}{cccc}1 & \rho_{1,2} & \cdots & \rho_{1, \mathrm{n}} \\ \rho_{2,1} & 1 & \cdots & \rho_{2, \mathrm{n}} \\ \vdots & \vdots & \ddots & \vdots \\ \rho_{\mathrm{n}, 1} & \rho_{\mathrm{n}, 2} & \cdots & 1\end{array}\right]$

where $\rho_{\mathrm{i}, \mathrm{j}}$ is the correlation coefficient between two random variables $x_{\mathrm{i}}$ and $x_{\mathrm{j}}(\mathrm{i} \neq \mathrm{j})$. 
For the non-normal distributions, the basic idea is to calculate the equivalent normal mean $\mu^{N}$ and equivalent standard deviation $\sigma^{N}$, which replaces the values of $\mu$ and $\sigma$ in Equation 1. The Rackwitz-Fiessler transformation defines the following analytical solution for $\boldsymbol{\mu}^{N}$ and $\sigma^{N}$ [15]:

$\mu^{N}=x-\sigma^{N} \Phi^{-1}[F(x)]$

$\sigma^{N}=\frac{\phi\left\{\Phi^{-1}[F(x)]\right\}}{f(x)}$

In Equation 3, $\Phi^{-1}[\cdot]$ is the inverse of the cumulative distribution function (CDF) (standard normal), and $F(x)$ is the original non-normal CDF, evaluated for $\boldsymbol{x}$. In Equation 4, $\phi\{\}$ is the probability density function (pdf) of the standard normal distribution, whereas $f(x)$ is the original non-normal pdf, evaluated for $\boldsymbol{x}$.

In a classical explanation, $\beta$ is the smallest distance from the mean value point to the limit state surface in units of directional standard deviations [7]. Low and Tang [5], [7] proposed an alternative interpretation of the reliability index $\beta$, which is a simple method of defining the index, in the original space of the random variables, through the perspective of an expanding ellipsoid. Figure 1 shows this interpretation.

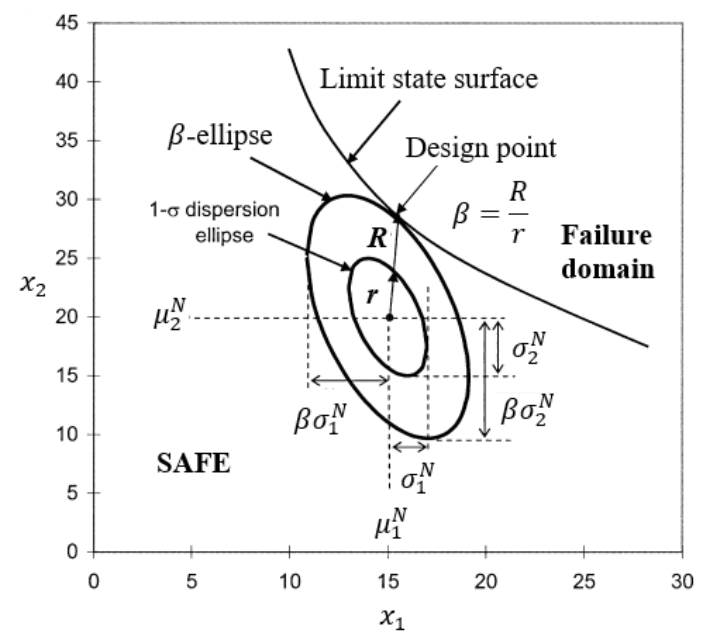

Figure 1. Equivalent dispersion ellipsoids illustrated in the plane [8].

As shown in Figure 1, the design point is a tangency point of the expanding dispersion ellipsoid with the limit state surface, which separates safe values from unsafe values (failure domain). The reliability index $\beta$ is the axis ratio $R / r$ of the ellipse that touches the limit state surface [8]. The dispersion ellipsoid expands from the mean-value point according to the following probability density function of a multivariate normal distribution [8]:

$$
f(x)=\frac{1}{(2 \pi)^{\frac{n}{2}}|C|^{0.5}} \exp \left[-\frac{1}{2} \beta^{2}\right]
$$

where to minimize $\beta$, defined by Equation 1, is to maximize the value of the probability density function defined by Equation 5. Hence, it is possible to define the smallest dispersion ellipsoid tangent to the limit state surface (see Figure 1) and the most probable failure point (design point). 
Low and Tang [5] described that if each axis of the $(1-\sigma)$ dispersion ellipsoid, in Figure 1, is parallel to the coordinate axis, the random variables are uncorrelated. So, in correlated normal random variables, each axis of the $(1-\sigma)$ dispersion ellipsoid is inclined about the coordinate axis.

The index $\beta$ is particularly useful in evaluating the failure probability through the application of the CDF of $\beta$, $\Phi(\beta)$, and considering standard normal variables [9]:

$p_{\mathrm{f}} \approx 1-\Phi(\beta)$

Low and Tang [8] performed a new efficient algorithm using FORM, where the first and third terms under the square root in Equation 1 are equivalent standard vectors $[n]$. Thus, Equation 1 is defined as:

$$
\beta=\min _{x \in F} \sqrt{[n]^{T}[\mathbf{R}]^{-1}[n]}
$$

The optimization routine Solver of Microsoft Excel solves Equation 7. Autonomously, the routine changes the values of components $n_{\mathrm{i}}$ (computing the parameters $\boldsymbol{\mu}^{N}$ and $\sigma^{N}$, when necessary) and subjecting the limit state function to a zero-value restriction. The components in the original space, $x_{\mathrm{i}}$, are program-calculated from:

$$
x_{\mathrm{i}}=F^{-1}\left[\Phi\left(n_{\mathrm{i}}\right)\right]
$$

\subsection{Monte Carlo Simulation}

The Monte Carlo Simulation (MCS) consists of developing an analytical and numerical model and using many simulations or cycles to check the real behavior of a system. Each cycle provides output variables (results) based on random input variables, using statistical methods and probability distributions [16].

Considering a random variable $X$, with a $\operatorname{CDF} F_{X}\left(x_{\mathrm{i}}\right)$, to generate sample $x_{\mathrm{i}}$ values included in $X$, the MCS code needs to accomplish some steps. First, MATLAB numerical procedures generate a sample value of $u_{\mathrm{i}}$ between 0 and 1 for a random variable with uniform distribution. Next, the inverse of $F_{X}$ computes a sample value of $x_{\mathrm{i}}\left(x_{\mathrm{i}}=F_{X}^{-1}\left(u_{\mathrm{i}}\right)\right)$.

For two correlated normal random variables, the numerical procedure generates two random numbers $u_{1}$ and $u_{2}$, used to compute the random variables $x$ and $y$ from the following equations [17]:

$$
x=\mu_{X}+\sigma_{X} \sqrt{-2 \ln u_{1}} \cos \left(2 \pi u_{2}\right)
$$

$$
y=\mu_{Y \mid X}+\sigma_{Y \mid X} \sqrt{-2 \ln u_{1}} \sin \left(2 \pi u_{2}\right)
$$

where the mean and standard deviation of the variable $y$, which are dependent on $x$ value, are evaluated through the following equations:

$$
\begin{aligned}
& \mu_{Y \mid X}=\mu_{Y}+\rho_{X, Y} \frac{\sigma_{Y}}{\sigma_{X}}\left(x-\mu_{X}\right) \\
& \sigma_{Y \mid X}=\sigma_{Y} \sqrt{1-\left(\rho_{X, Y}\right)^{2}}
\end{aligned}
$$


Each MCS cycle consists of introducing random input variables in an appropriated mathematical model: the limit state or performance functions $Z=g\left(x_{1}, x_{2}, \ldots, x_{\mathrm{n}}\right)=0$. A negative performance function implies random variables located in a failure domain. After the implementation of all cycles, the following relation, between the total failure cycles $N_{\mathrm{f}}$ and the total cycles of MCS $N$, checks the failure probability $p_{\mathrm{f}}[15]$ :

$p_{\mathrm{f}}=\frac{N_{\mathrm{f}}}{N}$

Figure 2 shows a flowchart with the steps of the MCS numerical procedure developed in MATLAB. In summary, the numerical procedure considers a predefined number of cycles and checking the failure cycles, $N_{\mathrm{f}}$. Equation 14 checks the failure probability estimation error through a normal distribution approximation, with a reliability interval of $95 \%$.

$e(\%)=200 \times\left(\sqrt{\frac{1-p_{\mathrm{f}}}{N \times p_{\mathrm{f}}}}\right)$

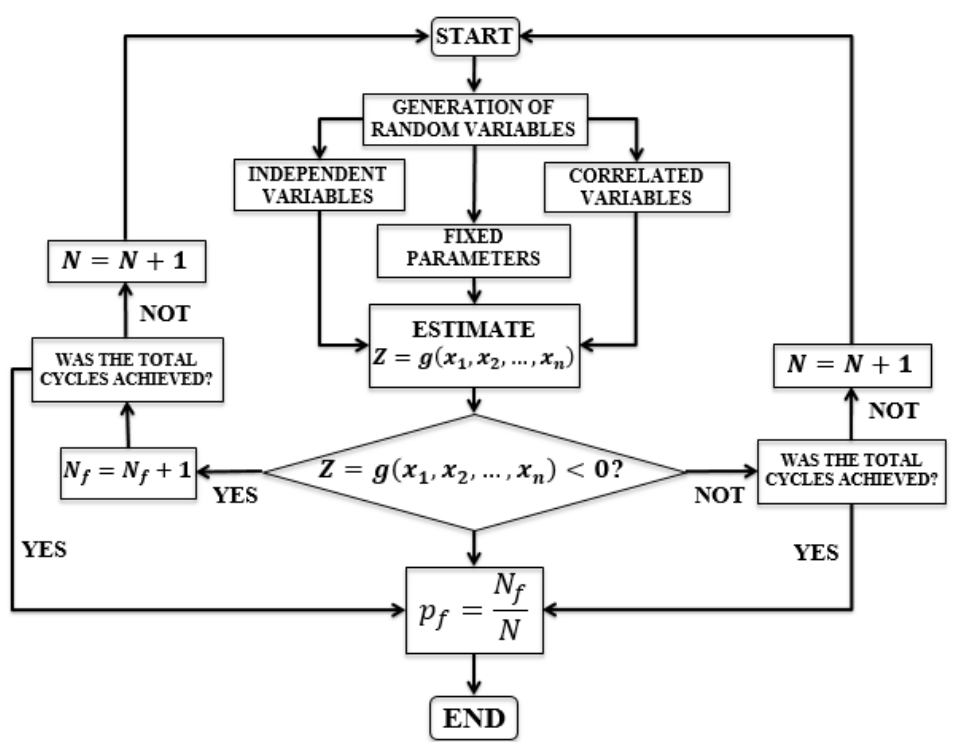

Figure 2. Flowchart of the MCS procedure.

\section{ANALYTICAL FRAMEWORK FOR ELASTOPLASTIC DEFORMATION IN AXISYMMETRIC TUNNELS}

\subsection{Elastoplastic fields in the surrounding rock mass}

Figure 3 shows the axisymmetric tunnel characteristics, excavated in a homogeneous elastic-plastic rock mass and with a radius $R_{\mathrm{i}}$. The cylindrical coordinate system $\underline{e}_{r}, \underline{e}_{\theta}$, and $\underline{e}_{z}$ represents the stress and displacement components. The stresses $\sigma_{\text {rr }}(r)$ and $\sigma_{\theta \theta}(r)$ are the in-plane normal components of the rock stress tensor $\underline{\underline{\sigma}}$, whereas $P_{\infty}$ and $P_{\mathrm{i}}$ is the far-field pressure and uniform support pressure into the excavation. It is assumed that the stress component $\sigma_{\mathrm{zz}}(r)$ does not vary, which implicitly amounts to disregarding the confinement losses along the z-axis direction. 


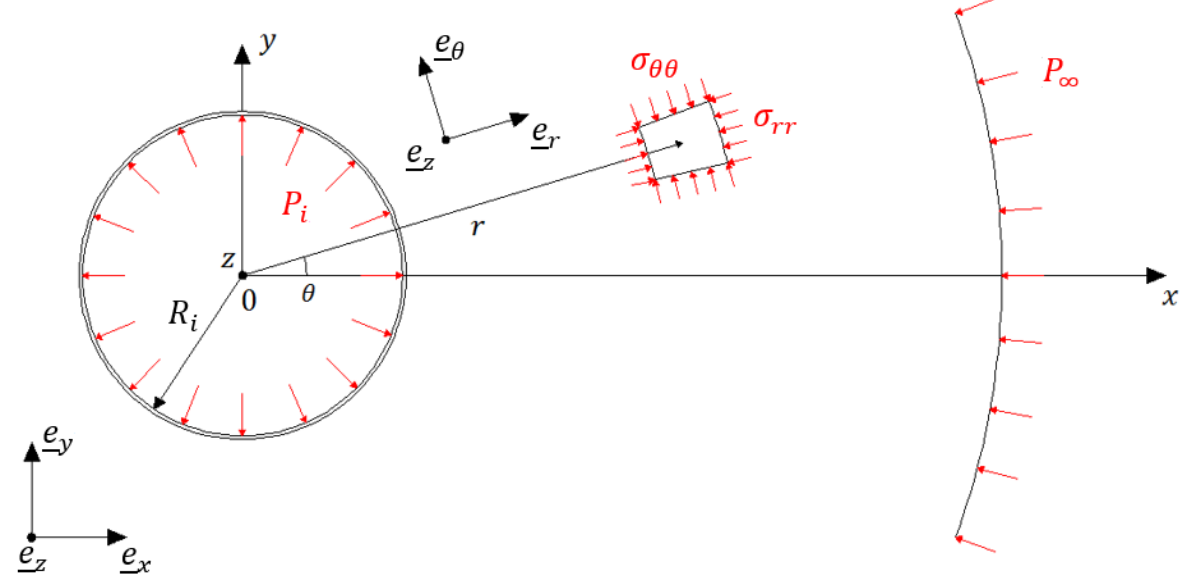

Figure 3. Cross-section of an axisymmetric tunnel within an elastic-plastic rock mass.

In the fully elastic regime, the radial displacement $u_{\mathrm{ie}}(r)$ at any a point of the rock mass located at distance $r$ from the center of the excavation is given by ([18], [19]):

$u_{\mathrm{ie}}(r)=-\left(\frac{1+v}{E}\right)\left(P_{\infty}-P_{i}\right) \frac{R_{i}^{2}}{r}$

where $v$ and $E$ are the Poisson's rate and Young's modulus, respectively.

In the elastoplastic regime, the mechanical analysis of the tunnel deformation indicates that two regions should be distinguished, as illustrated in Figure 4: the elastoplastic region $R_{\mathrm{i}} \leq r \leq R_{\mathrm{p}}$ undergoing irreversible strains, and the elastic behavior region $r \geq R_{\mathrm{p}}$. The plastic radius $r=R_{\mathrm{p}}$ defines the limit between the elastic and elastoplastic regions of the rock mass.

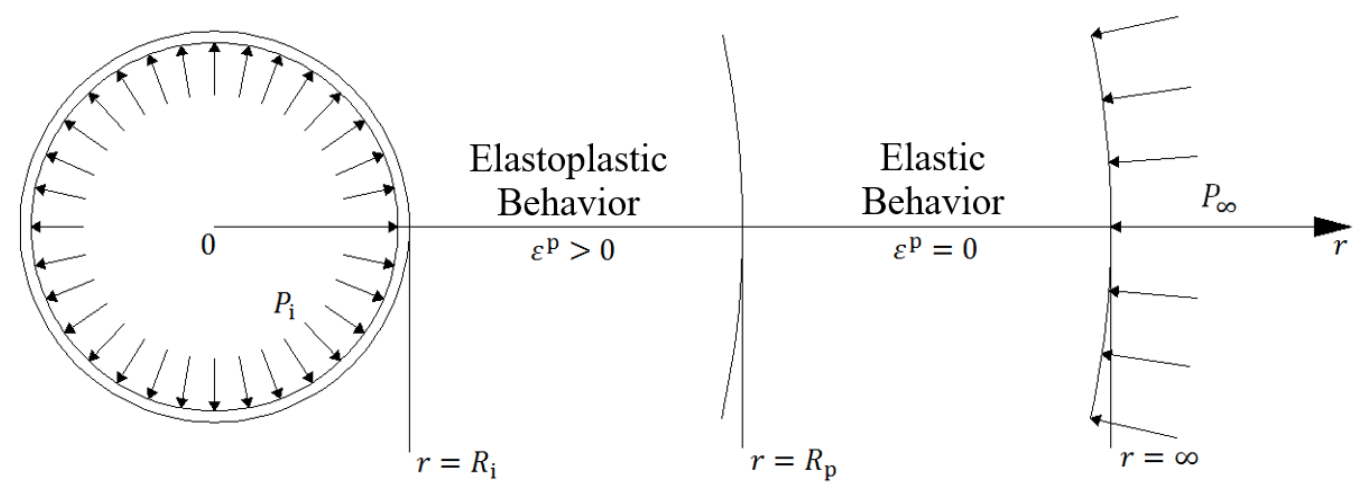

Figure 4. Axisymmetric tunnel within an elastoplastic rock mass.

The analytical methods use the M-C criterion concepts for the elastoplastic behavior, defined according to Salençon [18] and Corbetta [19]. The plastic radius $R_{\mathrm{p}}$ is:

$R_{\mathrm{p}}=R_{\mathrm{i}}\left[\frac{2\left(P_{\infty}+a\right)}{\left(K_{\mathrm{p}}+1\right)\left(P_{\mathrm{i}}+a\right)}\right]^{\frac{1}{K_{\mathrm{p}}-1}}$ 
where:

$K_{\mathrm{p}}=\frac{1+\sin \varphi}{1-\sin \varphi}$

$a=\frac{c}{\tan \varphi}$

in which $c$ is the cohesion and $\varphi$ is the friction angle. The limit pressure $P_{\text {im }}$ defines a rock mass pressure when $r=R_{\mathrm{p}}$ as follows:

$P_{\lim }=\frac{2 P_{\infty}+a\left(1-K_{\mathrm{p}}\right)}{\left(K_{\mathrm{p}}+1\right)}$

Referring to Figure 4, the radial displacement $u_{\mathrm{ip}}$ in the elastoplastic region $R_{\mathrm{i}} \leq r \leq R_{\mathrm{p}}$ is defined by:

$u_{\text {ip }}(r)=r\left(\frac{1+v}{E}\right)\left[A+B\left(\frac{r}{R_{\mathrm{p}}}\right)^{K_{\mathrm{p}}-1}+C\left(\frac{R_{\mathrm{p}}}{r}\right)^{K_{\mathrm{b}}+1}\right]$

where Equation 21 defines the dilatancy coefficient $K_{\mathrm{b}}, \psi$ representing the dilatancy angle, whereas Equations 22,23 and 24 characterize the parameters $A, B$, and $C$.

$K_{b}=\frac{1+\sin \psi}{1-\sin \psi}$

$A=(1-2 v)\left(P_{\infty}+a\right)$

$B=-\left[\frac{(1-v)\left(K_{\mathrm{b}} K_{\mathrm{p}}+1\right)}{K_{\mathrm{p}}+K_{\mathrm{b}}}\right]\left[\frac{2\left(P_{\infty}+a\right)}{\left(K_{\mathrm{p}}+1\right)}\right]$

$C=-2(1-v)\left[\frac{\left(K_{p}-1\right)\left(P_{\infty}+a\right)}{K_{p}+K_{b}}\right]$

\subsection{Convergence-confinement method}

The CV-CF method allows modeling in a simplified manner the evolution of normalized radial displacement $U_{\mathrm{i}}$ of the rock mass and support, or the convergence at the tunnel wall, associated with the internal pressure $P_{1}$ in a specific cross-section of the tunnel wall. The convergence $U_{\mathrm{i}}$ is given by:

$U_{\mathrm{i}}=\frac{\left|u_{\mathrm{i}}\left(r=R_{\mathrm{i}}\right)\right|}{R_{\mathrm{i}}}$ 
where $u_{\mathrm{i}}\left(r=R_{\mathrm{i}}\right)$ is the radial displacement at the tunnel wall, defined by Equation 15 (elastic behavior) or Equation 20 (elastoplastic behavior). The principle of the CV-CF method is schematized in Figure 5.

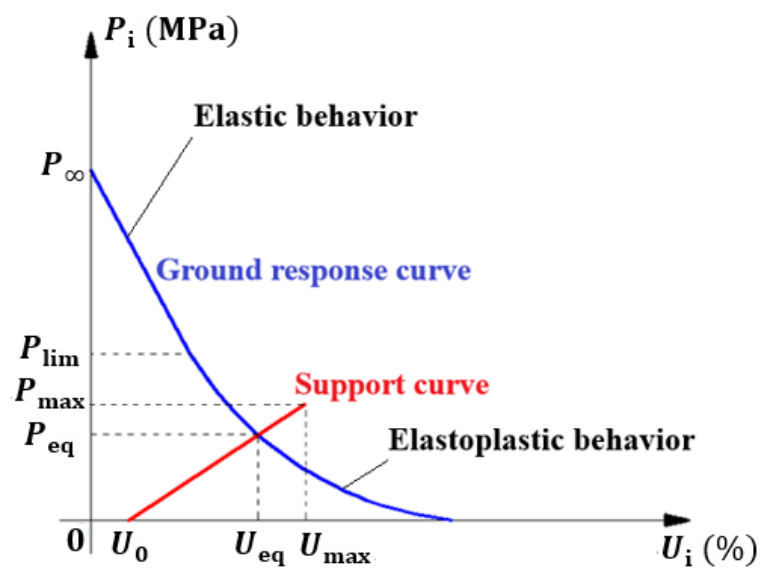

Figure 5. Schematized description of the Convergence-confinement method for a specific cross-section of a tunnel.

Figure 5 shows the Ground response curve, or Convergence curve (CV), which describes only the mechanical behavior of the unsupported excavation wall, while the Support curve, or Confinement curve (CF), describes the mechanical behavior of the elastic shotcrete lining.

When the excavation front is close to a specific cross-section, changes occur in the ground stress state. At some distance, before the excavation reaches the cross-section, there are small changes of the stress state, and elastic convergence $U_{\mathrm{ie}}$ occurs as $P_{\mathrm{i}}$ decreases. The internal pressure $P_{\mathrm{i}}$ continues to decrease where, eventually, the decrement of stresses in the rock mass will reach a limit $P_{\mathrm{lim}}$, and the stresses cause plastic behavior of the ground in a zone with a radius $R_{\mathrm{p}}$ surrounding the tunnel periphery [12]. Thus, considering an interval $P_{\infty} \geq P_{\mathrm{i}} \geq P_{\text {lim }}$, the CV curve shows an elastic behavior (blue curve in Figure 5), and for the interval $P_{\mathrm{im}} \geq P_{1} \geq 0$, the CV curve shows an elastoplastic behavior. Equations 16 and 19 defines $R_{\mathrm{p}}$ and $P_{\mathrm{im}}$.

The CF curve avoids the ground confinement loss, which causes normalized radial displacements of the rock mass. According to the red curve in Figure 5, a ground confinement loss generates a growing internal pressure $P_{\mathrm{i}}$ and convergence $U_{\mathrm{i}}$ on the cross-section lining. Moreover, numerical or analytical approaches estimate the convergence $U_{0}$ at the beginning of the support installation. Panet and Guenot [20] proposed an analytical approximation for $U_{0}$ :

$U_{0}=\left[1-\left(\frac{0.84 R_{\mathrm{p}}}{d_{0}+0.84 R_{\mathrm{p}}}\right)^{2}\right]\left[U_{\mathrm{i}, \infty}-0.27\left(\frac{1+v}{E} P_{\infty}\right)\right]+0.27\left(\frac{1+v}{E} P_{\infty}\right)$

where $U_{\mathrm{i}, \infty}$ is the convergence for elastoplastic behavior, at a larger distance between the excavation face and the crosssection (Equation 25 with $P_{1}=0$ ).

The pressure at the shotcrete lining is evaluated as [21]:

$P_{\mathrm{i}}=K_{\mathrm{s}}\left(U_{\mathrm{i}, \mathrm{s}}-U_{0}\right)$

In Equation 27, $U_{\mathrm{i}, \mathrm{s}}$ is the shotcrete convergence (determined when $P_{\mathrm{i}}$ varies between 0 and $P_{\max }$ in Equation 27), and $K_{\mathrm{S}}$ is the support stiffness coefficient, calculated according to the relation $R_{\mathrm{i}} / t_{\mathrm{S}}$ ([22], [23]): 
$\left\{\begin{array}{cl}K_{\mathrm{S}}=\frac{E_{\mathrm{S}}}{\left(1-v_{\mathrm{S}}\right)} \frac{t_{\mathrm{S}}}{R_{\mathrm{i}}} & \text { for } \frac{R_{\mathrm{i}}}{t_{\mathrm{s}}}>10 \\ K_{\mathrm{S}}=\frac{E_{S}\left[R_{i}^{2}-\left(R_{i}-t_{S}\right)^{2}\right]}{\left(1-v_{\mathrm{S}}\right)\left[\left(1-v_{\mathrm{S}}\right) R_{\mathrm{i}}^{2}+\left(R_{i}-t_{s}\right)^{2}\right]} & \text { for } \frac{R_{\mathrm{i}}}{t_{\mathrm{s}}} \leq 10\end{array}\right.$

where $t_{\mathrm{S}}$ is the shotcrete lining thickness, while $\mathrm{E}_{\mathrm{S}}$ and $v_{\mathrm{S}}$ are the Young modulus and the Poisson Coefficient of the support, respectively. The maximum support pressure $P_{\max }$ is defined by the following Equation:

$\begin{cases}P_{\max }=\frac{\sigma_{\mathrm{s}} t_{\mathrm{s}}}{R_{\mathrm{i}}} & \text { for } \frac{R_{\mathrm{i}}}{t_{\mathrm{s}}}>10 \\ P_{\max }=\frac{\sigma_{\mathrm{S}}}{2}\left[1-\frac{\left(R_{\mathrm{i}}-t_{\mathrm{S}}\right)^{2}}{R_{\mathrm{i}}^{2}}\right] & \text { for } \frac{R_{\mathrm{i}}}{t_{\mathrm{s}}} \leq 10\end{cases}$

$\sigma_{\mathrm{s}}$ standing for the uniaxial compressive strength of the support lining.

The maximum convergence $U_{\max }$ is evaluated by setting $P_{1}=P_{\max }$ into Equation 27. Referring to Figure 5, the equilibrium state of the structure $\left(U_{\mathrm{i}}=U_{\text {eq }}\right.$ and $\left.P_{\mathrm{i}}=P_{\text {eq }}\right)$ is defined as the intersection point between the $\mathrm{CV}$ and $\mathrm{CF}$ curves. The design value $P_{\text {eq }}$ can be computed combining Equations 16, 20 and 27:

$P_{\mathrm{eq}}-K_{\mathrm{c}}\left\{\left(\frac{1+v}{E}\right)\left[A+B\left(\frac{R_{\mathrm{i}}}{R_{\mathrm{p}}}\right)^{K_{\mathrm{p}}-1}+C\left(\frac{R_{\mathrm{p}}}{R_{\mathrm{i}}}\right)^{K_{\mathrm{b}}+1}\right]-U_{0}\right\}=0$

By using Equation 16 one can calculate $R_{\mathrm{p}}$ with $P_{\mathrm{i}}=P_{\mathrm{eq}}$. Then Equation 30 is solved numerically by the bisection method inside the MCS MATLAB code.

\section{PERFORMANCE FUNCTIONS AND ADOPTED PARAMETERS}

The limit state function, or performance function, $g_{1}(x)$ refers to the plastic zone's reliability analyses, whereas $g_{2}(x)$ refers to the shotcrete lining reliability. The functions $g_{1}(x)$ and $g_{2}(x)$ consider the relationship between an accepted resistance and a demand (loading), according to the equations below ([9], [13]):

$g_{1}(x)=L-\frac{R_{\mathrm{p}}}{R_{\mathrm{i}}}=L-\left[\frac{2\left(P_{\infty}+a\right)}{\left(K_{\mathrm{p}}+1\right)\left(P_{\mathrm{i}}+a\right)}\right]^{\frac{1}{K_{\mathrm{p}}-1}}$

$g_{2}(x)=U_{\max }-U_{\text {eq }}=R_{\mathrm{i}}\left[\frac{P_{\max }+P_{\mathrm{eq}}+2 K_{\mathrm{s}} U_{0}}{K_{\mathrm{S}}}\right]$

The ratios $L$ and $U_{\max }$ are the allowed largest values (resistances) for the following demands (loadings): plastic zone ratio $\left(R_{\mathrm{p}} / R_{\mathrm{i}}\right)$ and design convergence ratio $\left(U_{\mathrm{eq}}\right)$. Equation 31 evaluates $R_{\mathrm{p}} / R_{\mathrm{i}}$ using Equation 16, while Equation 32 evaluates $U_{\max }$ by fixing $U_{\mathrm{i}, \mathrm{s}}=U_{\max }$ in Equation 27, with $P_{1}=P_{\max }$. When $g_{1}(x)$ takes a negative value, an unacceptable large plastic zone occurs, and it exceeds the $L$ ratio. If $g_{2}(x)$ takes a negative value, the radial displacement $U_{\text {eq }}$ exceeds the largest support displacement $U_{\max }$. 
The geotechnical random variables were obtained in the research of Hoek [6] (tunnel A) and Brantmark [24] (tunnel B). Tables 1 and 2 show the geotechnical statistical parameters for tunnels A and B.

Table 1. Geotechnical statistical parameters for tunnel A [6].

\begin{tabular}{cccc}
\hline Geotechnical parameter & Mean $(\mu)$ & Standard Deviation $(\sigma)$ & Coefficient of Variation $(\delta)$ \\
\hline Friction angle $(\varphi)$ & $22.85^{\circ}$ & $1.31^{\circ}$ & 0.06 \\
\hline Cohesion $(c)$ & $0.230 \mathrm{MPa}$ & $0.068 \mathrm{MPa}$ & 0.30 \\
\hline Deformation modulus $(E)$ & $373 \mathrm{MPa}$ & $48 \mathrm{MPa}$ & 0.13 \\
\hline Far field stress $\left(P_{\infty}\right)$ & $2.50 \mathrm{MPa}$ & $0.25 \mathrm{MPa}$ & 0.10 \\
\hline
\end{tabular}

Table 2: Geotechnical statistical parameters for tunnel B [24].

\begin{tabular}{cccc}
\hline Geotechnical parameter & Mean $(\mu)$ & Standard Deviation $(\sigma)$ & Coefficient of Variation $(\delta)$ \\
\hline Friction angle $(\varphi)$ & $35.00^{\circ}$ & $0.50^{\circ}$ & 0.01 \\
\hline Cohesion $(c)$ & $1.30 \mathrm{MPa}$ & $0.13 \mathrm{MPa}$ & 0.10 \\
\hline Deformation modulus $(E)$ & $5000 \mathrm{MPa}$ & $500 \mathrm{MPa}$ & 0.10 \\
\hline Far field stress $\left(P_{\infty}\right)$ & $8.00 \mathrm{MPa}$ & $0.80 \mathrm{MPa}$ & 0.10 \\
\hline
\end{tabular}

All statistical parameters described in Tab. 1 and 2 are normally distributed. However, it is considered a negative correlation between $c$ and $\varphi$, with the following correlation coefficients: $\rho_{c, \varphi}=-0.5$ for tunnel A and $\rho_{c, \varphi}=-0.9$ for tunnel B. It should be emphasized that the correlation between some of the design parameters significantly affects the reliability predictions. In that respect, the assumption of negatively correlated shear strength parameters was found to be conservative with respect to uncorrelated variables [25]. The analysis developed, for instance, in Laso et al. [4] has included the correlation between some of the relevant problem parameters, such as correlation between the ground Young modulus and ground density, shotcrete average resistance and shotcrete layer thickness, as well as between tunnel radius and shotcrete layer thickness. Although the subject of correlation is not fully addressed in the present reliability study, this important issue will be foreseen in the continuation line of this research.

The rock mass failure criterion features a non-associated flow rule in both tunnels, with the following deterministic parameters: $\psi=0$ and $K_{\mathrm{b}}=1$ (Equation 21) for tunnel A; $\psi=20^{\circ}$ and $K_{\mathrm{b}}=2.04$ for tunnel B. The Poisson coefficients are $v=0.30$, and $v=0.25$, for tunnels A and B, respectively. For both tunnels, a radius of $R_{\mathrm{i}}=4.5 \mathrm{~m}$ is adopted.

Table 3 shows the statistical parameters for the shotcrete lining. Both tunnels use the same parameters, which are statistically independent and normally distributed. The Poisson coefficient is $v_{\mathrm{c}}=0.25$.

Table 3. Statistical parameters of shotcrete support [24].

\begin{tabular}{cccc}
\hline Shotcrete parameter & Mean $(\mu)$ & Standard Deviation $(\sigma)$ & Coefficient of Variation $(\delta)$ \\
\hline Deformation modulus $\left(E_{\mathrm{S}}\right)$ & $16,000 \mathrm{MPa}$ & $800 \mathrm{MPa}$ & 0.05 \\
\hline Uniaxial compressive strength $\left(\sigma_{\mathrm{s}}\right)$ & $30 \mathrm{MPa}$ & $1.5 \mathrm{MPa}$ & 0.05 \\
\hline
\end{tabular}

Li and Low [9] suggested applying the lognormal or beta distribution instead of the normal distribution when the coefficient of variation a random variable (ratio between standard deviation and mean) is 0.25 or higher. This is necessary to avoid negative geotechnical parameters, which is irrational. All coefficients of variation are smaller than 0.25 in tunnels A and B, except for the cohesion $c$ in tunnel A, where, alternatively, the cohesion is constrained to be greater than zero. 


\section{RELIABILITY ANALYSIS REGARDING THE EXTENT OF PLASTIC ZONE}

This section analyzes the reliability of tunnels A and B, contemplating the performance function of Equation 31 . The first reliability analysis performs the characterization of the fixed resistances in $g_{1}(x)$ regarding unsupported tunnels, whereas the second analysis of the reliability methods will contemplate the shotcrete lining. The 2007 FORM algorithm of Low and Tang and MCS compute the reliability indexes and failure probabilities, employing the analytical theories explained in section 2.

In summary, the Low and Tang algorithm is a code developed in Visual Basic (VBA) language and Microsoft Excel. A constrained optimization routine, denominated Solver, assists in the FORM procedure development, where the equations and parameters described in sections 2.1 and 4 have been employed directly in the Excel worksheets. Low and Tang [7], [8], and Li and Low [9] give more details about the FORM algorithm of Low and Tang.

First, it is necessary to verify the results obtained by FORM and MCS to check the algorithms' proper operation. Li and Low [9] analyzed the plastic zone reliability, employing the FORM Low and Tang code, the performance function $g_{1}(x)$, and tunnel A parameters. Thus, Table 4 shows a comparison between results of this work and $\mathrm{Li}$ and Low [9], with the following deterministic values: the parameters of tunnel A, $P_{\infty}=2.50 \mathrm{MPa}, L=3.00,0 \leq P_{1} \leq 0.30 \mathrm{MPa}$ and $5 \mathrm{E}+06$ Monte Carlo simulations, which generates an error between $0.15 \% \leq e \leq 3.92 \%$ when $0 \leq P_{1} \leq 0.30 \mathrm{MPa}$.

Table 4: Failure probabilities results $p_{\mathrm{f}}$ considering tunnel A.

\begin{tabular}{|c|c|c|c|}
\hline \multirow[b]{2}{*}{$P_{1}(\mathrm{MPa})$} & \multicolumn{2}{|c|}{ Results of this work } & \multirow{2}{*}{$\begin{array}{c}\text { Li and Low [9] } \\
\text { FORM Low and Tang }\end{array}$} \\
\hline & FORM Low and Tang & MCS & \\
\hline 0 (unsupported tunnel) & $24.30 \%$ & $24.68 \%$ & $24.40 \%$ \\
\hline 0.10 & $6.26 \%$ & $6.42 \%$ & $6.31 \%$ \\
\hline 0.20 & $0.87 \%$ & $0.89 \%$ & $0.88 \%$ \\
\hline 0.30 & $0.06 \%$ & $0.05 \%$ & $0.06 \%$ \\
\hline
\end{tabular}

The failure probabilities evaluated in Tab. 4 have shown a good agreement with the Li and Low [9] results, considering both FORM and MCS results of this work. Thus, considering random variables with normal distribution, the reliability algorithms used in this work have shown efficiency when applied in unsupported and supported tunnels analysis.

The first analysis intends to verify the influence of resistance $L$ in the reliability index $\beta$, on the plastic zone reliability in tunnels A and B. Figure 6 shows the $\beta$ values evaluated for the statistical parameters of unsupported tunnels A and B, employing FORM Low and Tang algorithm, and varying the resistance $L$, in Equation 31, considering the following intervals: $2.30 \leq L \leq 3.00$ for tunnel A and $1.10 \leq L \leq 1.70$ for tunnel B.

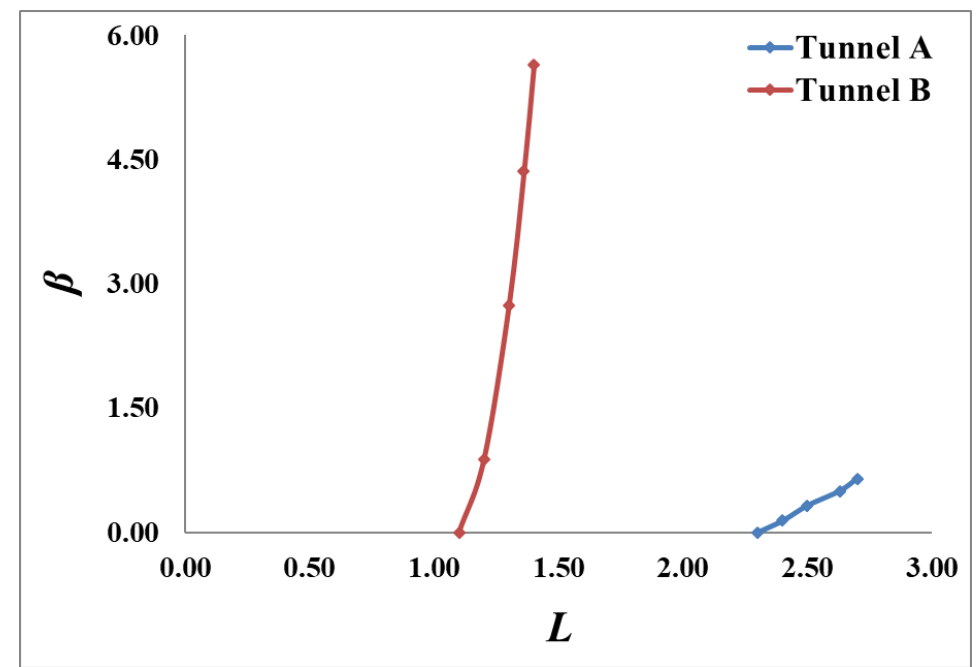

Figure 6. Reliability index results with the variation of the resistance $L$, regarding unsupported tunnels $\mathrm{A}$ and $\mathrm{B}\left(P_{\mathrm{i}}=0\right)$. 
Comparing the curves in Figure 6, a great sensibility on the $\beta$ variation with the increase of $L$ occurs for tunnel B (red curve). For example, the index in tunnel $\mathrm{B}$ increases from $\beta=0.88$ to $\beta=2.74$ if the resistance increases from $L=1.40$ to $L=1.50$. On the other hand, tunnel A (blue curve) does not show a considerable increase in $\beta$, i.e., the index increases from $\beta=0.14$ to $\beta=0.32$ when $L$ increases from $L=2.70$ to $L=2.80$. Table 5 illustrates the values of $\beta$ and $p_{\mathrm{f}}$ according to the curves of Figure 6 .

Table 5. Reliability index and failure probabilities of the plastic zone.

\begin{tabular}{|c|c|c|c|c|c|}
\hline \multicolumn{3}{|c|}{ TUNNEL A } & \multicolumn{3}{|c|}{ TUNNEL B } \\
\hline$L$ & $\beta$ & $p_{\mathrm{f}}(\%)$ & $L$ & $\beta$ & $p_{\mathrm{f}}(\%)$ \\
\hline 2.70 & 0.14 & 44.45 & 1.40 & 0.88 & 18.85 \\
\hline 2.80 & 0.32 & 37.30 & 1.50 & 2.74 & 0.31 \\
\hline 2.90 & 0.50 & 31.12 & 1.60 & 4.35 & $6.82 \mathrm{E}-4$ \\
\hline 3.00 & 0.65 & 25.86 & 1.70 & 5.64 & $8.57 \mathrm{E}-7$ \\
\hline
\end{tabular}

The results of Tab. 5 highlight the $p_{\mathrm{f}}$ reduction in both studies. In tunnel A, $p_{\mathrm{f}}$ decreases from $44.45 \%$ to $25.86 \%$ between $L=2.70$ and $L=3.00$, while in tunnel B $p_{\mathrm{f}}$ decreases from $18.85 \%$ to $8.57 \mathrm{E}-07 \%$ between $L=1.40$ and $L=1.70$. In contrast, the reliability index $\beta$ increases from 0.14 to 0.65 for tunnel A and from 0.88 to 5.64 for tunnel B, with $L$ variation. The greater variation of reliability results in tunnel $\mathrm{B}$ is a consequence of the correlation between the random variables and the plastic zone results $R_{\mathrm{p}} / R_{\mathrm{i}}$, performed by MCS.

Figure 7 illustrates the correlation between the random variables and $R_{\mathrm{p}} / R_{\mathrm{i}}$ through dispersion charts, using $30 \mathrm{E}+03$ Monte Carlo simulations. The number of simulations was varied to assess the accuracy of the MCS results. The errors in estimating the failure probability were $1.28 \%$ and $2.40 \%$, checked through Equation 14 , using the parameters of unsupported tunnels $\mathrm{A}$ and $\mathrm{B}\left(P_{\mathrm{i}}=0\right)$.

There is a strong correlation between the plastic zone and the parameters $\left(c, \varphi\right.$ and $\left.P_{\infty}\right)$ in tunnel B (Figures 7b). It does not occur with tunnel A parameters, which are more dispersed than tunnel B parameters (Figures 7a). About these figures, when the resistance $L$ is close to the plastic zone average, $L \approx \mu_{R_{\mathrm{p}} / R_{\mathrm{i}}} \approx 2.70$, the $R_{\mathrm{p}} / R_{\mathrm{i}}$ results are more dispersed in the failure zone $(L>2.70)$. Due to this, the reliability results of tunnel A, in Figure 6 and Table 5, shows a low variation when adopting $2.30 \leq L \leq 3.00$. In contrast, when $L \approx \mu_{R_{\mathrm{p}} / R_{\mathrm{i}}} \approx 1.40$ for tunnel $\mathrm{B}$, the strong correlation causes a little $R_{\mathrm{p}} / R_{\mathrm{i}}$ dispersion in the failure zone $(L>1.40)$, and a great variation in reliability results when adopting $1.10 \leq L \leq 1.70$.

In an overall analysis, these results say that the designers must be careful when adopting elevated values for $L$, in reliability analysis that involves highly correlated parameters. For this purpose, this study adopted the average resistance values in the performance function $g_{1}(x): L=1.40$ for tunnel $\mathrm{B}$, and, for comparison purposes, $L=2.70$ for tunnel A.

Turning now to the shotcrete lining tunnels, the Low and Tang FORM algorithm and MCS estimates the plastic zone reliability through Equation 31. Tables 6 and 7 summarizes the $\beta$ and $p_{\mathrm{f}}$ results of the plastic zone. The following interval constraints the shotcrete lining pressure $P_{\mathrm{i}}: 0.10 \mathrm{MPa} \leq P_{i} \leq 0.50 \mathrm{MPa}$. The MCS results for $P_{\mathrm{i}}=0.1$ and $0.2 \mathrm{MPa}$ consider 30E +03 simulations in both tunnels, whereas the MCS results for $P_{1}=0.3$ and $0.4 \mathrm{MPa}$ consider $20 \mathrm{E}+06$ simulations in both tunnels. Regarding $P_{1}=0.5 \mathrm{MPa}$, the MCS results refer to $10 \mathrm{E}+07$ simulations for tunnel A and $20 \mathrm{E}+06$ simulations for tunnel B. The number of simulations increases with $P_{\mathrm{i}}$ to keep the error below $10 \%$.

The results in Tables 6 and 7 show that $p_{\mathrm{f}}$ is greater in tunnel $\mathrm{A}$ than in tunnel $\mathrm{B}$, when the support pressure $P_{\mathrm{i}} \leq 0.3 \mathrm{MPa}$, whereas the opposite occurs when $P_{\mathrm{i}} \geq 0.4 \mathrm{MPa}$. This shows the importance of adopting an appropriate lining for tunnel safe. The $p_{\mathrm{f}}$ and $\beta$ results obtained by the Low and Tang Algorithm and MCS show good concordance. The $P_{\mathrm{i}}$ variation in both tunnels reported reductions of $p_{\mathrm{f}}$ and increases in $\beta$. 


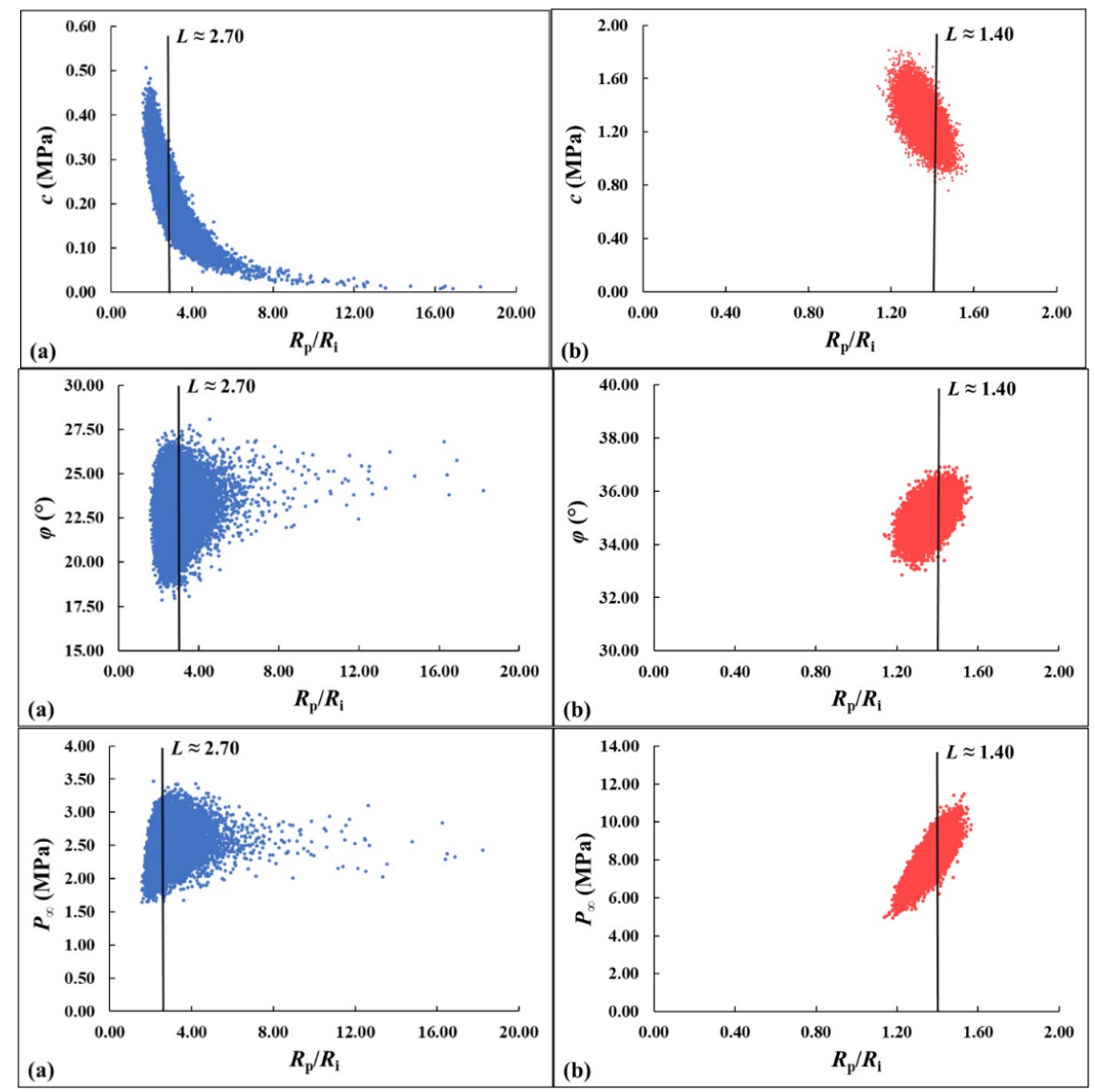

Figure 7. Dispersion results of the plastic zone $\left(R_{\mathrm{p}} / R_{\mathrm{i}}\right)$ regarding cohesion $(c)$, friction angle $(\varphi)$, and far-field stress $\left(P_{\infty}\right)$ : (a) Tunnel A; (b) Tunnel B.

Table 6. Reliability results for the performance function $g_{1}(x)$ of tunnel A.

\begin{tabular}{cccccc}
\hline & \multicolumn{2}{c}{ Low and Tang Algorithm } & \multicolumn{2}{c}{ MCS } \\
\cline { 2 - 5 } Support Pressure $\left(P_{\mathrm{i}}\right) \mathbf{( M P a )}$ & $\beta$ & $p_{\mathrm{f}} \mathbf{( \% )}$ & $p_{\mathrm{f}}(\mathbf{\%})$ & $e \mathbf{( \% )}$ \\
\hline 0 (unsupported) & 0.14 & 44.27 & 44.75 & 1.28 \\
\hline 0.10 & 0.95 & 17.09 & 3.40 & 2.52 \\
\hline 0.20 & 1.76 & 3.90 & 3.94 & 5.68 \\
\hline 0.30 & 2.58 & 0.50 & 0.51 & 0.63 \\
\hline 0.40 & 3.39 & 0.04 & 0.03 & 2.56 \\
\hline 0.50 & 4.19 & $1.38 \mathrm{E}-03$ & $7.90 \mathrm{E}-04$ & 7.12 \\
\hline
\end{tabular}

Table 7. Reliability results for the performance function $g_{1}(x)$ of tunnel B.

\begin{tabular}{|c|c|c|c|c|}
\hline \multirow{2}{*}{ Support Pressure $\left(P_{\mathrm{i}}\right)(\mathbf{M P a})$} & \multicolumn{2}{|c|}{ Low and Tang Algorithm } & \multicolumn{2}{|c|}{ MCS } \\
\hline & $\beta$ & $p_{\mathrm{f}}(\mathbf{\%})$ & $p_{\mathrm{f}}(\%)$ & $e(\%)$ \\
\hline 0 (unsupported) & 0.88 & 18.85 & 18.75 & 2.40 \\
\hline 0.10 & 1.46 & 7.22 & 7.21 & 4.14 \\
\hline 0.20 & 2.05 & 2.04 & 2.04 & 7.99 \\
\hline 0.30 & 2.64 & 0.41 & 0.43 & 0.68 \\
\hline 0.40 & 3.25 & 0.06 & 0.06 & 1.81 \\
\hline 0.50 & 3.86 & $5.58 \mathrm{E}-03$ & $5.80 \mathrm{E}-03$ & 5.88 \\
\hline
\end{tabular}


The MCS code provides the plastic zone histograms in Figures 8a and 8b, where the MATLAB application Distribution Fitter adjusts probability distribution functions with these histograms.

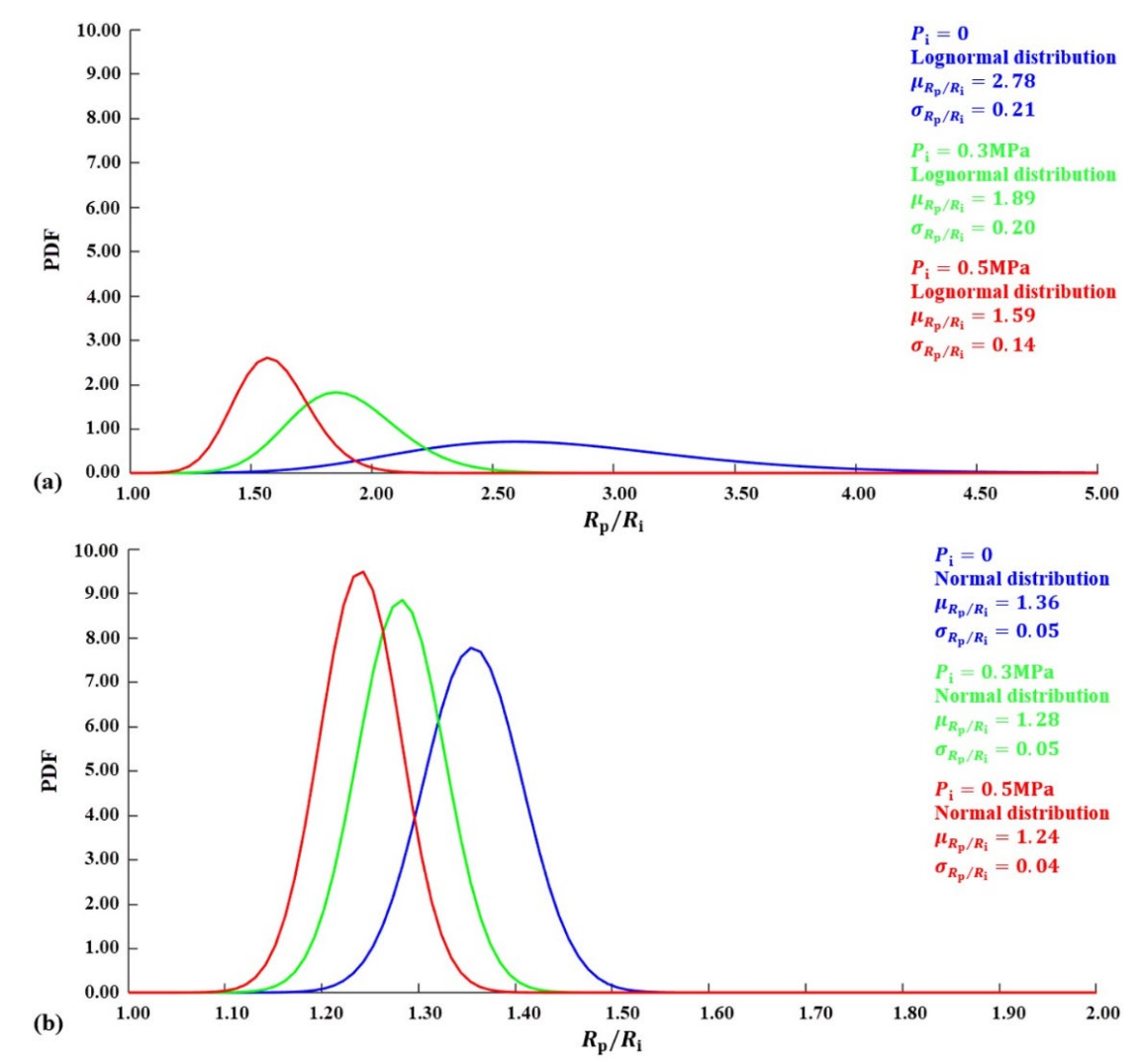

Figure 8. Probability Distribution Functions (PDF) of the plastic zone through Monte Carlo simulations: (a) Tunnel A; (b) Tunnel B.

The plastic zone intervals of PDF curves of Tunnel B (Figure 8b) is smaller than the intervals of tunnel A (Figure 8a). It occurs because the standard deviations $\left(\sigma_{R_{\mathrm{p}} / R_{\mathrm{i}}}\right)$ for tunnel $\mathrm{B}$ are smaller than the $\sigma_{R_{\mathrm{p}} / R_{\mathrm{i}}}$ values of tunnel A. Also, the mean values $\left(\mu_{R_{\mathrm{p}} / R_{\mathrm{i}}}\right)$ of tunnel $\mathrm{B}$ are smaller than $\mu_{R_{\mathrm{p}}} / R_{\mathrm{i}}$ of tunnel $\mathrm{A}$, due to the higher geotechnical parameters of tunnel $\mathrm{B}$.

Figures $8 \mathrm{a}$ and $8 \mathrm{~b}$ emphasize the histogram distribution types. Tunnel A fits the Lognormal distribution for all histograms, whereas tunnel B fits the Normal distribution for all histograms.

All PDF curves exhibit reductions in the statistical parameters when $P_{\mathrm{i}}$ increases. In Figure 8a, the mean and standard deviation reduces from $\mu_{R_{\mathrm{p}} / R_{\mathrm{i}}}=2.78$ and $\sigma_{R_{\mathrm{p}} / R_{\mathrm{i}}}=0.21 \quad\left(P_{\mathrm{i}}=0\right)$ to $\mu_{R_{\mathrm{p}} / R_{\mathrm{i}}}=1.59$ and $\sigma_{R_{\mathrm{p}}} / R_{\mathrm{i}}=0.14 \quad\left(P_{\mathrm{i}}=0.5 \mathrm{MPa}\right)$, whereas in Figure 8b, the parameters reduce from $\mu_{R_{\mathrm{p}} / R_{\mathrm{i}}}=1.36$ and $\sigma_{R_{\mathrm{p}} / R_{\mathrm{i}}}=0.05 \quad\left(\mathrm{P}_{\mathrm{i}}=0\right)$ to $\mu_{R_{\mathrm{p}} / R_{\mathrm{i}}}=1.24$ and $\sigma_{R_{\mathrm{p}} / R_{\mathrm{i}}}=0.04$ $\left(P_{1}=0.5 \mathrm{MPa}\right)$. To summarize, the $P_{1}$ increasing causes the reliability index increasing and failure probability reduction during the reliability analyses.

\section{RELIABILITY ANALYSIS REGARDING THE TUNNEL CONVERGENCE}

In this section, the reliability analysis evaluates the probability of $P_{\mathrm{eq}}$ and $U_{\mathrm{eq}}$ exceeding the allowed parameters $P_{\max }$ and $U_{\max }$. The MCS employs the CV-CF method linked with the performance function $g_{2}(x)$ (Equation 32). The shotcrete lining parameters are those described in section 4 and Table 3.

As evaluated in the previous section, Equation 14 checks the MCS accuracy considering some number of simulations and a shotcrete lining thickness $t_{\mathrm{c}}=10 \mathrm{~cm}$. This work adopts $5 \mathrm{E}+06$ simulations, which generate the following results for tunnels A and B: $p_{\mathrm{f}}=4.06 \%$ with an error of $0.43 \%$ and $p_{\mathrm{f}}=19.21 \%$ with an error of $0.18 \%$. 
Figure 9 shows the variation of the failure probability $\left(p_{\mathrm{f}}\right)$ with the increase of $t_{\mathrm{c}}$. The results were obtained using $5 \mathrm{E}+06 \mathrm{MCS}$ cycles for each $t_{\mathrm{c}}$, where in tunnel A the error varies between $0.43 \% \leq e \leq 6.02 \%$ regarding $10 \mathrm{~cm} \leq t_{\mathrm{c}} \leq 13 \mathrm{~cm}$, and in tunnel B the error varies between $0.18 \% \leq e \leq 3.32 \%$ regarding $10 \mathrm{~cm} \leq t_{\mathrm{c}} \leq 20 \mathrm{~cm}$. The increase of $t_{\mathrm{c}}$ produces a considerable $p_{\mathrm{f}}$ reduction in tunnel A. The increase of just one centimeter in $t_{\mathrm{c}}$ of tunnel A reduces $p_{\mathrm{f}}$ from $4.06 \%$ $\left(t_{\mathrm{c}}=10 \mathrm{~cm}\right)$ to $0.93 \%\left(t_{\mathrm{c}}=11 \mathrm{~cm}\right), p_{\mathrm{f}}$ arrives at $0.02 \%$ when $t_{\mathrm{c}}=13 \mathrm{~cm}$. With the tunnel B parameters, Figure 9 shows a reduction from $p_{\mathrm{f}}=19.21 \%\left(t_{c}=10 \mathrm{~cm}\right)$ to $p_{\mathrm{f}}=1.15 \%\left(t_{\mathrm{c}}=16 \mathrm{~cm}\right), p_{\mathrm{f}}$ arrives at $0.08 \%$ when $t_{\mathrm{c}}=20 \mathrm{~cm}$. These results say that tunnel B needs more shotcrete than tunnel A to get acceptable reliability levels due to the far-field pressure in tunnel $\mathrm{B}$ is much higher than in tunnel $\mathrm{A}$.

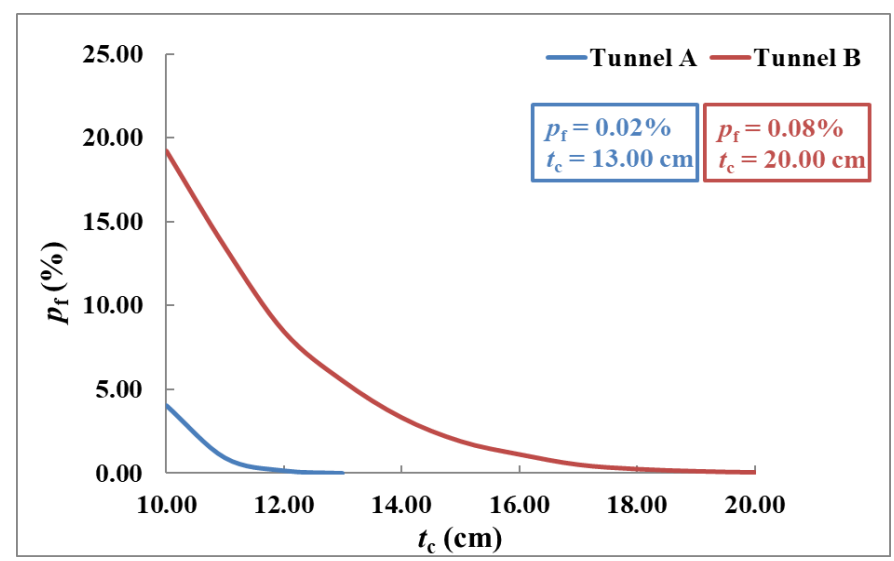

Figure 9. Failure probability reduction with the increasing of $t_{\mathrm{c}}$, concerning the performance function $g_{2}(x)$.

Table 8 exhibits the design and maximum support parameters, considering $t_{\mathrm{c}}=13 \mathrm{~cm}$ for tunnel $\mathrm{A}$ and $t_{\mathrm{c}}=20 \mathrm{~cm}$ for tunnel B, which keep an adequate structural safety level for the support $\left(p_{\mathrm{f}}<0.10 \%\right)$. The convergences $U_{\mathrm{eq}}$ and $U_{\max }$ have been calculated using the convergence $U_{0}$ of the support installation as the origin, whereas the radial displacements $u_{\mathrm{eq}}$ and $u_{\max }$ have been calculated through Equation 25, i.e., $u_{\mathrm{eq}}=\left|U_{\mathrm{eq}} \times R_{\mathrm{i}}\right|$ and $u_{\max }=\left|U_{\max } \times R_{\mathrm{i}}\right|$.

Table 8. Statistical design parameters for the shotcrete support.

\begin{tabular}{|c|c|c|c|c|c|c|c|c|c|c|c|c|}
\hline & \multicolumn{2}{|c|}{$P_{\text {eq }}(\mathrm{MPa})$} & \multicolumn{2}{|c|}{$P_{\max }(\mathrm{MPa})$} & \multicolumn{2}{|c|}{$U_{\text {eq }}(\%)$} & \multicolumn{2}{|c|}{$U_{\max }(\%)$} & \multicolumn{2}{|c|}{$u_{\text {eq }}(\mathrm{mm})$} & \multicolumn{2}{|c|}{$u_{\max }(\mathbf{m m})$} \\
\hline & $\mu$ & $\sigma$ & $\mu$ & $\sigma$ & $\mu$ & $\sigma$ & $\mu$ & $\sigma$ & $\mu$ & $\sigma$ & $\mu$ & $\sigma$ \\
\hline Tunnel A & 0.53 & 0.11 & 0.87 & 0.04 & 0.11 & 0.02 & 0.18 & 0.01 & 4.70 & 1.00 & 7.93 & 0.56 \\
\hline Tunnel B & 0.91 & 0.11 & 1.33 & 0.07 & 0.12 & 0.01 & 0.18 & 0.01 & 5.40 & 0.64 & 7.93 & 0.56 \\
\hline
\end{tabular}

The results in Table 8 reveal a difference of $72 \%$ between the $P_{\mathrm{eq}}$ mean values for tunnels A and $\mathrm{B}$, whereas the difference between the $U_{\text {eq }}$ mean values is only $9 \%$. Concerning $P_{\max }$ and $U_{\max }$, the thickness $t_{\mathrm{c}}$ controls the support resistance, which increases the stiffness value $\left(K_{\mathrm{c}}\right)$ and $P_{\max }$, but does not change $U_{\max }$ in both tunnels.

Figures $10 \mathrm{a}$ and $10 \mathrm{~b}$ illustrate the failure probability through the $u_{\mathrm{eq}}$ and $u_{\max }$ histograms obtained with the parameters of Table 8 .

The histograms in Figures 10a and 10b show the support failure region, between 6.00 and $7.00 \mathrm{~mm}$ approximately, where $g_{2}(x)<0$. The area of this region is proportional to the failure probability, $p_{\mathrm{f}}$. From Figure 9 , it can be seen that $p_{\mathrm{f}}$ on $t_{\mathrm{c}}=13 \mathrm{~cm}$ (tunnel A) and $t_{\mathrm{c}}=20 \mathrm{~cm}$ (tunnel B) have close values. This occurs due to $u_{\mathrm{eq}}$ standard deviations since the $u_{\mathrm{eq}}$ histogram in Figure 10a is sparser than the corresponding histogram in Figure 10b. As well as in Figure 10, it is easy to evaluate the failure probability through $g_{2}(x)$, according to Figures $11 \mathrm{a}$ and $11 \mathrm{~b}$. 

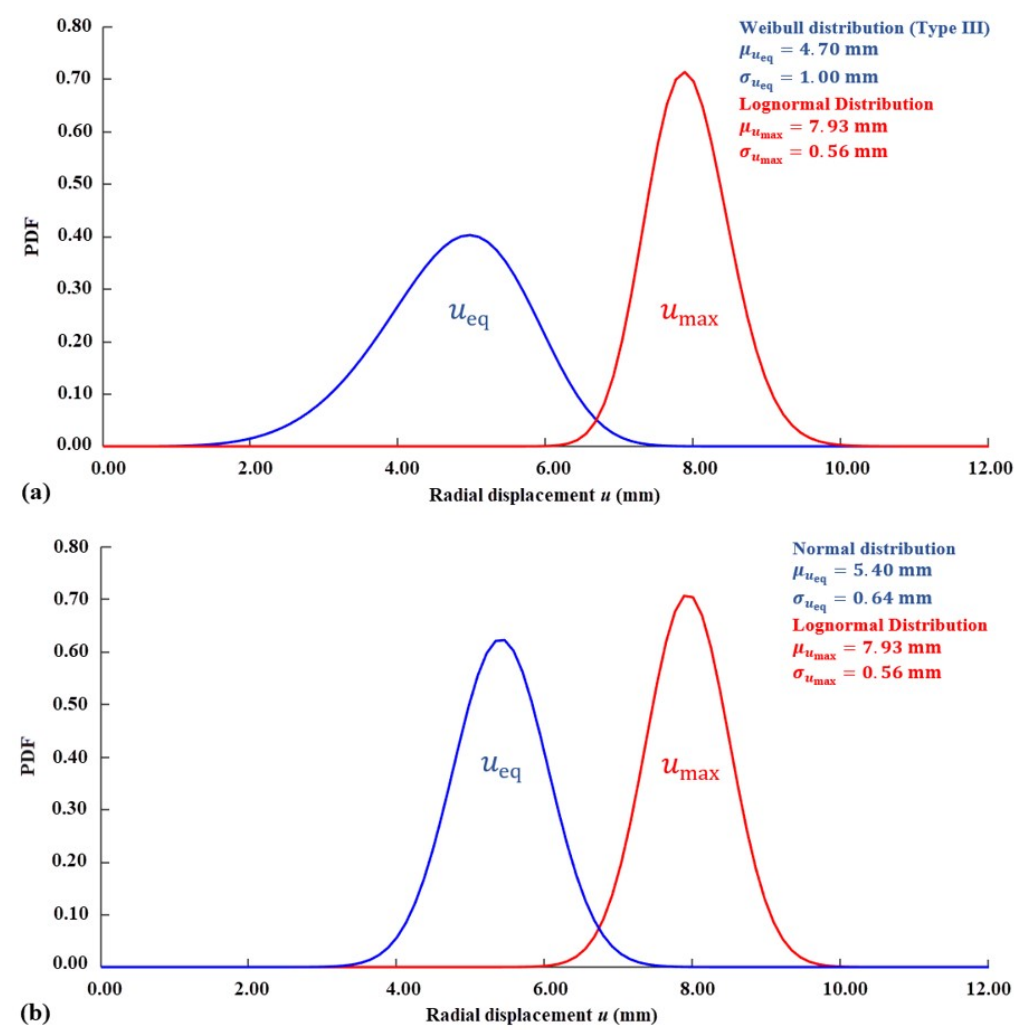

Figure 10. Demand and resistance histograms, generated using 5E+06 Monte Carlo simulations: (a) Tunnel A; (b) Tunnel B.
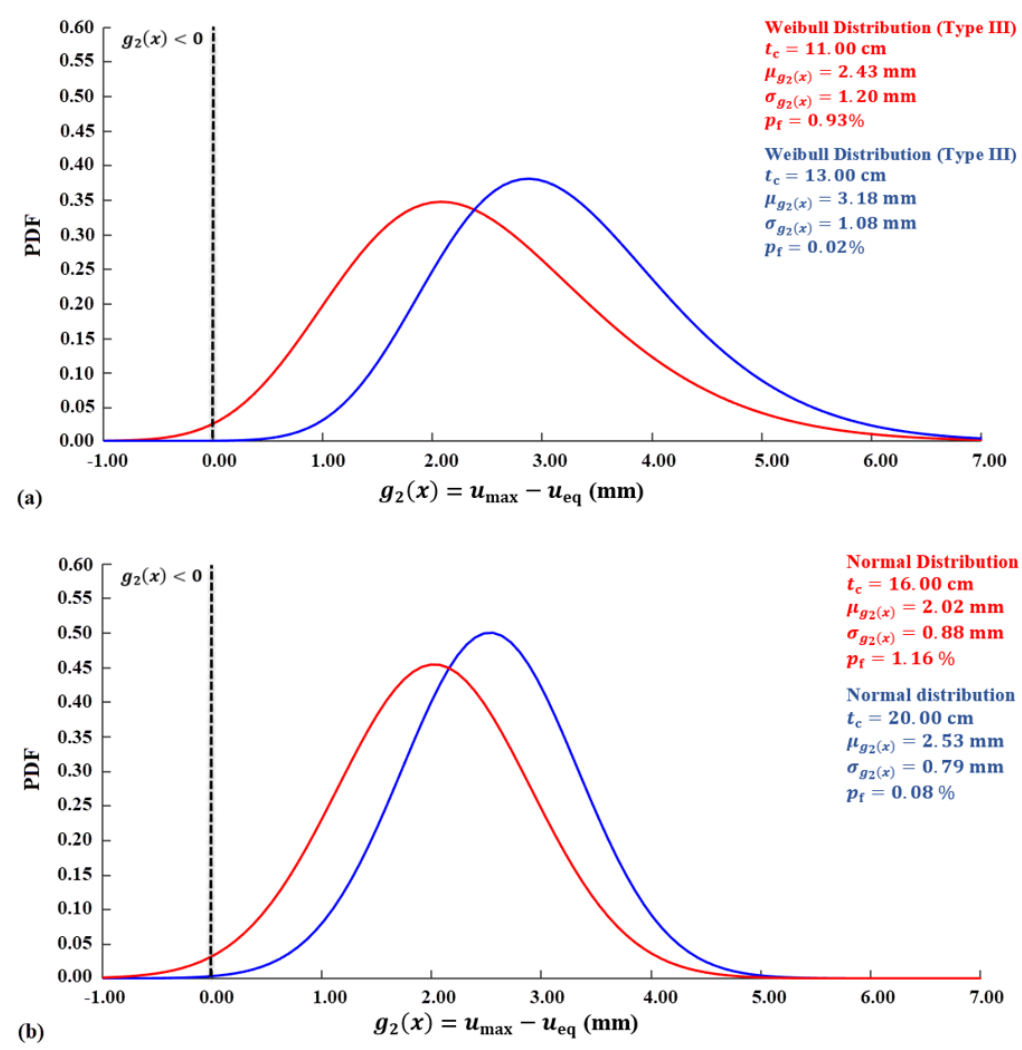

Figure 11. Histograms of performance function $g_{2}(x)$, generated using Monte Carlo simulations: (a) Tunnel A; (b) Tunnel B. 
The negative values of $g_{2}(x)$, located on the left side of the dashed line in Figures 11a and 11b represents a failure point of the shotcrete lining. That is to say that the area below the histograms and on the left side of the dashed line (in Figure 11) has the same value of the failure probability, $p_{\mathrm{f}}$. It is possible to see in Figures 11a and 11b, that this area reduces with the increase of $t_{\mathrm{c}}$, and, therefore, also reduces $p_{\mathrm{f}}$. Similar to earlier findings, the standard deviation in tunnel A is greater than tunnel B in histograms of Figure 11.

Figures 12a and $12 \mathrm{~b}$ show an analysis through the CV-CF method, using the mean values of tunnels $\mathrm{A}$ and $\mathrm{B}$ to verify the accordance with the results defined in Table 8 . In these cases, it has been considered $t_{\mathrm{c}}=13 \mathrm{~cm}$ and $t_{\mathrm{c}}=20 \mathrm{~cm}$ for tunnels A and B, respectively. The results in Figure 12 must be interpreted with caution due to $U_{\text {eq }}$ referring to the shotcrete lining displacement, which starts from the displacement $U_{0}$.

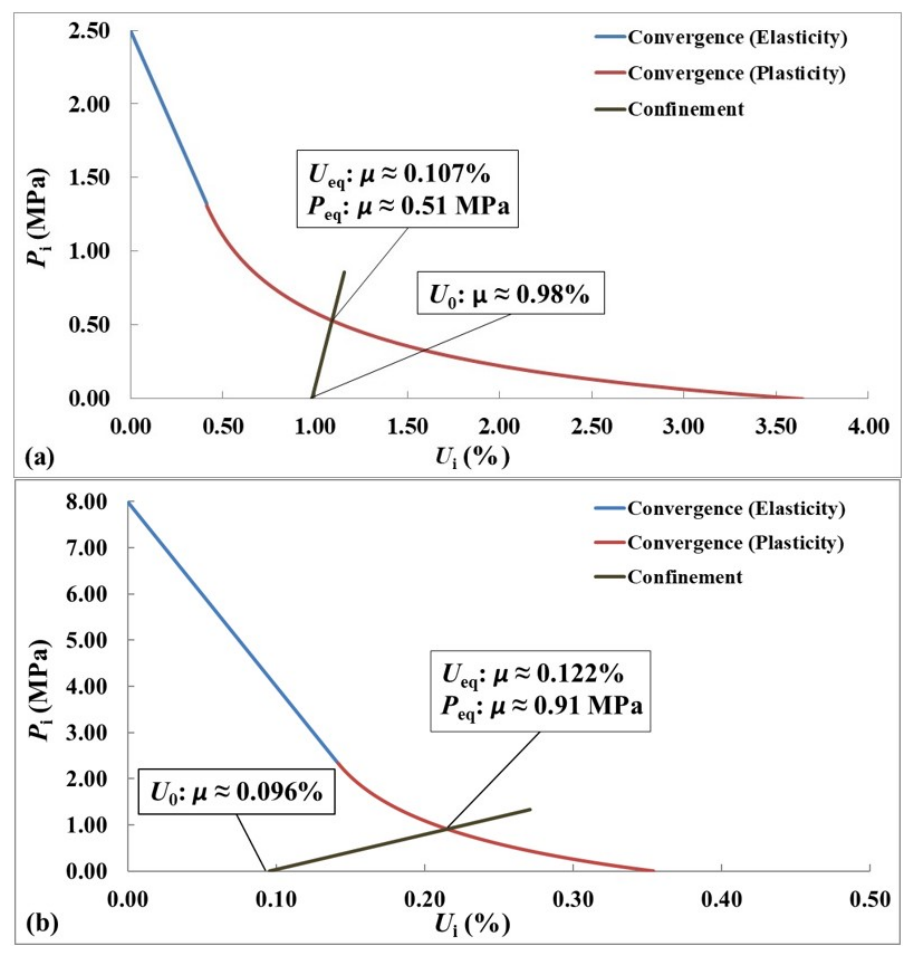

Figure 12. CV-CF method analysis with mean values of: (a) tunnel A; (b) tunnel B.

There are similarities between the design parameters defined in Figures 12a and $12 \mathrm{~b}$ and the design parameters of Table 8, where it can be seen that the interaction between the Convergence and Confinement curves has been influencing the reliability analysis. The Confinement curve of tunnel A tends to perform better than tunnel B due to the internal pressure $P_{\mathrm{i}}$ being higher in tunnel $\mathrm{B}$.

These results suggest that the shotcrete lining of tunnel A, considering $t_{\mathrm{c}}=13 \mathrm{~cm}$, produces acceptable stiffness results $K_{\mathrm{s}}$, which increases the inclination of the Convergence curve in Figure 12. Tunnel B, likewise, produces acceptable $K_{\mathrm{S}}$ results using $t_{\mathrm{c}}=20 \mathrm{~cm}$. The designer must consider adopting support parameters higher than the before adopted, aiming to increase $K_{\mathrm{S}}$, thus keeping the failure probability low.

\section{SUMMARY AND CONCLUSIONS}

This study performed a reliability analysis in deep axisymmetric tunnels, integrating FORM and MCS methods with tunnel analytical methodologies. VBA and MATLAB codes verified the reliability in rock masses and shotcrete lining, examining two different tunnels. 
The first aim was to check the plastic zone reliability through VBA FORM and MATLAB MCS algorithms. The reliability results verification has shown an excellent agreement between the reliability indexes and failure probabilities, obtained by both algorithms, and with the Li and Low [9] results.

The reliability study of the variation in the resistance $L$, considering unsupported tunnels, suggests that, in general, it is necessary to pay attention to the adopted $L$ value in rock masses with low dispersion. This work recommends adopting a resistance value $L$ around the mean value to avoid higher $p_{\mathrm{f}}$ values.

The increase of internal pressure $P_{1}$ produces great changes in the plastic zone reliability. Both tunnels develop significant $p_{\mathrm{f}}$ reductions when $P_{\mathrm{i}}=0.3 \mathrm{MPa}: p_{\mathrm{f}}$ reduces $43.80 \%$ in tunnel $\mathrm{A}$ and $18.40 \%$ in tunnel $\mathrm{B}$. The support pressure $P_{1}=0.3 \mathrm{MPa}$ maintains reliability percentages above $99 \%$ in both tunnels; moreover, for $P_{\mathrm{i}} \geq 0.3 \mathrm{MPa}, p_{\mathrm{f}}$ results are close to $0 \%$.

The MCS code used the CV-CF method equations to provide the convergence reliability. A shotcrete thickness $t_{\mathrm{c}}=11 \mathrm{~cm}$ results $p_{\mathrm{f}}=0.93 \%$ in tunnel A, whereas $t_{\mathrm{c}}=16 \mathrm{~cm}$ results $p_{\mathrm{f}}=1.15 \%$ in tunnel $\mathrm{B}$. When $t_{\mathrm{c}}$ increases for $13 \mathrm{~cm}$ in tunnel A, the failure probability reduces to $p_{\mathrm{f}}=0.02 \%$; whereas for tunnel $\mathrm{B}, p_{\mathrm{f}}$ reduces to $0.02 \%$ when $t_{\mathrm{c}}$ increases to $20 \mathrm{~cm}$. These findings suggest that tunnel A must have a shotcrete thickness between $t_{\mathrm{c}}=11 \mathrm{~cm}$ and $t_{\mathrm{c}}=13 \mathrm{~cm}$. Tunnel B must have a shotcrete thickness between $t_{\mathrm{c}}=16 \mathrm{~cm}$ and $t_{\mathrm{c}}=20 \mathrm{~cm}$. In summary, the failure probabilities are smaller than $0.1 \%$, considering $t_{\mathrm{c}}=13 \mathrm{~cm}$ in tunnel A and $t_{\mathrm{c}}=20 \mathrm{~cm}$ for tunnel B. Moreover, the internal design pressure $P_{\mathrm{eq}}$ for these thicknesses is greater than $0.3 \mathrm{MPa}$, which keeps plastic zone failures close to zero.

This paper contributes to check safety or failure probabilities in tunnel design stages. The reliability codes provided statistical data for different rock mass parameters. So, designers and engineers can use these methodologies to ensure security in underground design.

A natural progression of this work is to link two-dimensional and three-dimensional numerical models with the reliability codes. Moreover, this study suggests using reliability analysis in different cross-section geometries and supports (steel lining, precast concrete lining, bolts).

\section{ACKNOWLEDGEMENTS}

The authors acknowledge UFRGS and FURG for their support and CNPq and CAPES for their research grants.

\section{CITATIONS}

[1] S. Kohno, "Reliability-based design of tunnel support systems," Ph.D. dissertation, Univ. Illinois, Urbana, United States of America, 1989.

[2] E. Laso, "Application of Level II reliability methods to the design of tunnels liners," Ph.D. dissertation, Univ. Politéc. Madrid, Madrid, Spain, 1991. [in Spanish].

[3] S. Kohno, A. H.-S. Ang, and W. H. Tang, "Reliability evaluation of idealized tunnel system," Struct. Saf., vol. 11, no. 1, pp. 81-93, 1992.

[4] E. Laso, M. S. G. Lera, and E. Alarcón, "A level II reliability approach to tunnel support design," Appl. Math. Model., vol. 19, no. 1, pp. 371-382, 1995.

[5] B. K. Low and W. H. Tang, "Efficient reliability evaluation using spreadsheet," J. Eng. Mech., vol. 123, no. 1, pp. 749-752, 1997.

[6] E. Hoek, "Reliability of Hoek-Brown estimates of rock mass properties and their impact on design," Int. J. Rock Mech. Min. Sci., vol. 35, no. 1, pp. 63-68, 1998.

[7] B. K. Low and W. H. Tang, "Reliability analysis using object-oriented constrained optimization," Struct. Saf., vol. 26, no. 1, pp. 69-89, 2004.

[8] B. K. Low and W. H. Tang, "Efficient spreadsheet algorithm for first-order reliability method," J. Eng. Mech., vol. 133, no. 1, pp. 1378-1387, 2007.

[9] H. Li and B. K. Low, "Reliability analysis of circular tunnel under hydrostatic stress field," Comput. Geotech., vol. 37, no. 1-2, pp. $50-58,2010$.

[10] Q. Lü and B. K. Low, "Probabilistic analysis of underground rock excavations using response surface method and SORM," Comput. Geotech., vol. 38, no. 8, pp. 1008-1021, 2011.

[11] L. Song, H.-Z. Li, C. L. Chan, and B. K. Low, "Reliability analysis of underground excavation in elastic-strain-softening rock mass," Tunn. Undergr. Space Technol., vol. 60, no. 1, pp. 66-79, 2016.

[12] W. Bjureland, J. Spross, F. Johansson, A. Prästings, and S. Larsson, "Reliability aspects of rock tunnel design with the observational method," Int. J. Rock Mech. Min. Sci., vol. 1, no. 98, pp. 102-110, 2017.

[13] A. M. Hasofer and N. C. Lind, "Exact and invariant second moment cod format," J. Eng. Mech., no. 100, pp. 111-121, 1974.

[14] A. K. Verma, D. R. Karanki, and S. Ajit, Reliability and Safety Engineering. London: Springer Verlag London Ltd., 2016. 
[15] A. S. Nowak and K. R. Collins, Reliability of Structures. New York: Mc Graw Hill, 2000.

[16] B. M. Ayyub and R. H. McCuen, Probability, Statistics, and Reliability for Engineers and Scientist, 1st ed. New York: Taylor \& Francis Group, 2011.

[17] A. H.-S. Ang and W. H. Tang, Probability Concepts in Engineering Planning and Design, vol. II: Decision, Risk, and Reliability, 1st ed. New York: John Wiley \& Sons, Inc., 1984.

[18] J. Salençon, "Contraction quasi-statique d'une cavite a symetrie spherique ou cylindrique dans un milieu elasto-plastique," Ann. Ponts Chaussees, vol. 4, pp. 231-236, 1969.

[19] F. Corbetta, "Nouvelles méthodes d'étude des tunnels profonds: calculs analytiques et numériques," Ph.D. dissertation, Éc. Natl. Super. Mines, Paris, France, 1990.

[20] M. Panet and A. Guenot, "Analysis of convergence behind the face of a tunnel”, in Tunnelling 82, Proc. 3rd Int. Symp., Brighton, 1982, pp. 197-204.

[21] D. Bernaud, “Tunnels profonds dans les milieux viscoplastiques: approaches experimentale et numerique,” Ph.D. dissertation, L’Ec. Natl. Ponts et Chaussées, Paris, France, 1991.

[22] M. Panet and P. Guellec, "Contribution à l'etude du Soutènement d'un Tunnel à l'Arrière du Front de Taille," in Proc. 3rd Int. Cong. Rock Mechanics, Denver, 1982.

[23] E. Hoek and E. T. Brown, Underground Excavations in Rock, 1st ed. London: E\&FN Spon, 1980.

[24] J. Brantmark, "Rock support in weak rock - a case study based on the Uri Project," Ph.D. dissertation, KTH Roy. Inst. Technol., Stockholm, Sweden, 1998.

[25] A. Hamrouni, D. Dias, and B. Sbartai, "Reliability analysis of shallow tunnels using the response surface methodology," Undergr. Space, vol. 1, no. 2, pp. 246-258, 2017.

Author contributions: CCCS: conceptualization, investigation, data curation, methodology, validation, writing, review, editing; MVR: conceptualization, data curation, formal analysis, project administration, supervision, review, editing; SM: conceptualization, formal analysis, project administration, supervision, review, editing.

Editors: David Oliveira, Guilherme Aris Parsekian. 